05

\title{
Подавление скачков пластической деформации магнитным полем при низкотемпературном деформировании двухкомпонентных сплавов
}

\section{(C) В.В. Малашенко}

Донецкий физико-технический институт им. А.А. Галкина, Донецк, Украина

Донецкий национальный университет, Донецк, Украина

E-mail: malashenko@fti.dn.ua

Поступило в Редакцию 22 марта 2019г.

В окончательной редакции 22 марта 2019г.

Принято к публикации 26 марта 2019г.

Исследовано движение дислокаций при низкотемпературном деформировании двухкомпонентных сплавов. Найдено условие, при котором возможно появление участка с отрицательной скоростной зависимостью предела текучести, что является причиной возникновения динамической неустойчивости и скачков пластической деформации. Получено выражение для критического магнитного поля, способного подавлять эти деформационные скачки.

Ключевые слова: дислокация, магнитное поле, прерывистая деформация.

DOI: 10.21883/PJTF.2019.12.47908.17801

Двухкомпонентные сплавы нашли широкое применение в различных отраслях промышленности. Их механические свойства в значительной степени определяются взаимодействием движущихся по кристаллу дислокаций с атомами второго компонента [1]. При этом пластическая деформация в определенной области температур и скоростей носит скачкообразный характер [2,3]. Скачки пластической деформации приводят к появлению деформационных полос. Одной из причин возникновения скачков пластической деформации является отрицательная скоростная зависимость предела текучести сплава [4]. Такая зависимость может возникнуть, в частности, в области независимых динамических взаимодействий движущейся дислокации с атомами второго компонента [5]. Отрицательная скоростная зависимость предела текучести приводит к возникновению динамической неустойчивости дислокационного движения, которая порождает скачки деформации. Глубже понять специфику этого взаимодействия позволяют эксперименты по низкотемпературной деформации [6-8]. При температуре $T<25 \mathrm{~K}$ фононные механизмы диссипации теряют свою эффективность, уступая ведущую роль электронному торможению (drag) дислокации. Величиной электронного торможения можно управлять с помощью постоянного магнитного поля $[9,10]$.

Подавление скачков пластической деформации является важной практической задачей. В работе [3] исследовалось подавление прерывистой деформации Портевена-Ле Шателье постоянным электрическим током в алюминий-магниевом сплаве АМг5. Авторы [11] изучали влияние постоянного магнитного поля на неустойчивость пластического течения (эффект Портевена-Ле Шателье) в закаленных кристаллах $\mathrm{NaCl}: \mathrm{Eu}$ при комнатных температурах. Подавление скачков низ- котемпературной деформации двухкомпонентных сплавов магнитным полем ранее не исследовалось. Анализ возможности такого подавления является целью настоящей работы.

Пусть бесконечная краевая дислокация совершает скольжение под действием постоянного внешнего напряжения $\sigma_{0}$ в положительном направлении оси $O X$ с постоянной скоростью $v$ в плоскости XOZ. Кристалл содержит хаотически распределенные атомы второго компонента. Линии дислокаций параллельны оси $O Z$, их векторы Бюргерса $\mathbf{b}=(b, 0,0)$ одинаковы и параллельны оси $O X$. Положение дислокации определяется функцией

$$
X=v t+w(z, t) .
$$

Здесь $w(z, t)$ - случайная величина, описывающая изгибные колебания дислокации, возбужденные ее взаимодействием с хаотически распределенными дефектами. Среднее значение этой величины по длине дислокации и по хаотическому распределению дефектов равно нулю.

Уравнение движения дислокации может быть представлено в следующем виде:

$$
m\left\{\frac{\partial^{2} X}{\partial t^{2}}-c^{2} \frac{\partial^{2} X}{\partial z^{2}}\right\}=b\left[\sigma_{0}+\sigma_{x y}^{d}\right]-B_{e} \frac{\partial X}{\partial t},
$$

где $\sigma_{x y}^{d}$ - компонента тензора напряжений, создаваемых атомами второго компонента на линии дислокации, $m$ - масса единицы длины дислокации (массы всех дислокаций считаем одинаковыми), $c$ - скорость распространения в кристалле поперечных звуковых волн, $B_{e}$ - константа электронного торможения дислокации.

Воспользовавшись теорией динамического взаимодействия структурных дефектов [5,12-14], силу динамиче- 
ского торможения (drag) движущейся краевой дислокации атомами второго компонента вычислим по формуле

$$
F_{d}=\frac{n b^{2}}{8 \pi^{2} m} \int d^{3} q\left|q_{x}\right| \cdot\left|\sigma_{x y}^{d}(\mathbf{q})\right|^{2} \delta\left(q_{x}^{2} v^{2}-\omega^{2}\left(q_{z}\right)\right),
$$

где $\omega\left(q_{z}\right)$ - спектр дислокационных колебаний, $n-$ объемная концентрация атомов. Исследуемый механизм диссипации заключается в необратимом переходе кинетической энергии поступательного движения дислокации в энергию ее изгибных колебаний в плоскости скольжения. Оценки показывают, что амплитуда дислокационных колебаний, обусловленных взаимодействием дислокации со структурными дефектами, может на два порядка превосходить амплитуду тепловых колебаний. Данный механизм весьма чувствителен к виду спектра дислокационных колебаний, прежде всего к наличию в нем щели:

$$
\omega^{2}\left(q_{z}\right)=c^{2} q_{z}^{2}+\Delta^{2}
$$

Спектральная щель может возникать в результате коллективного взаимодействия движущихся дислокаций ансамбля с данной дислокацией или в результате коллективного взаимодействия с ней атомов второго компонента. Рассмотрим случай, когда доминирующее влияние на формирование спектральной щели оказывает коллективное взаимодействие дислокации с точечными дефектами. Он реализуется при условии

$$
\rho<\frac{\chi}{b^{2}} \sqrt{n_{d}}
$$

где $\chi$ - параметр несоответствия точечного дефекта, $n_{d}$ - безразмерная концентрация этих дефектов, $\rho-$ плотность подвижных дислокаций. Для $b=3 \cdot 10^{-10} \mathrm{~m}$, $\chi=10^{-1}, n_{d}=10^{-2}-10^{-4}$ это условие выполняется для плотности подвижных дислокаций $\rho \leqslant 10^{15} \mathrm{~m}^{-2}$.

Полная сила торможения дислокации будет равна

$$
F=F_{d}+F_{e} .
$$

Здесь $F_{d}-$ сила динамического торможения дислокации атомами второго компонента, $F_{e}$ - сила электронного торможения, которая, согласно [9], имеет вид

$$
F_{e}=B_{e}(H) v, \quad B_{e}(H)=\frac{e \mu_{0} B_{e}(0) \tau}{m_{e}} H,
$$

где $e-$ заряд электрона, $m_{e}-$ его масса, $\mu_{0}-$ магнитная постоянная, $H-$ напряженность магнитного поля, $B_{e}(0)$ - константа электронного торможения при нулевом магнитном поле, $\tau$ - время свободного пробега электрона.

Сила динамического торможения дислокации структурными дефектами определяется величиной щели в спектре дислокационных колебаний [5], которая в данном случае создается коллективным взаимодействием атомов второго компонента с дислокацией и определяется выражением

$$
\Delta=\frac{c}{b}\left(n_{d} \chi^{2}\right)^{1 / 4}
$$

После выполнения необходимых вычислений получим выражение для полной силы динамического торможения дислокации точечными дефектами и электронами в следующем виде:

$$
F=\frac{B_{d} v}{1+\frac{v^{2}}{v_{d}^{2}}}+B_{e} v
$$

Здесь $B_{d}-$ константа динамического торможения дислокации атомами второго компонента,

$$
B_{d}=\frac{\mu b \chi}{c} \sqrt{n_{d}}, \quad v_{d}=b \Delta=c\left(n_{d} \chi^{2}\right)^{1 / 4},
$$

$\mu$ - модуль сдвига.

Анализ полученного выражения показывает, что скоростная зависимость силы торможения дислокации может иметь минимум и максимум при выполнении условия

$$
B_{d}>8 B_{e}
$$

Скоростная зависимость силы торможения при выполнении данного условия имеет участок с отрицательным наклоном. На этом участке происходит снижение динамического предела текучести при повышении скорости пластической деформации. Возникает динамическая неустойчивость дислокационного движения, что приводит к появлению скачков пластической деформации. Меняя величину постоянного магнитного поля, можно менять величину константы электронного торможения, тем самым устраняя участки отрицательной скоростной зависимости и подавляя вызванные ими скачки деформации.

Максимум скоростной зависимости силы торможения соответствует переходу от коллективного взаимодействия точечных дефектов с дислокацией к независимым столкновениям с ними. Соответствующая ему скорость $v_{d}$ не зависит от величины магнитного поля. Минимум находится в точке $v_{1}$

$$
v_{1}=v_{d} \sqrt{\frac{B_{d}}{B_{e}(H)}}
$$

Минимум кривой $F(v)$ соответствует переходу от области, где доминирующим является торможение дислокации атомами точечных дефектов $\left(v<v_{1}\right)$, к области доминирования электронного торможения $\left(v>v_{1}\right)$.

Прикладывая постоянное магнитное поле, мы повышаем силу электронного торможения. Когда она значительно превышает силу торможения точечными дефектами, максимум и минимум исчезают. Скоростная зависимость становится монотонной. Область динамической неустойчивости подавляется. Вместе с ней исчезают и порожденные этой неустойчивостью скачки деформации.

Величина критического магнитного поля, способного подавить эти деформационные скачки, определяется выражением

$$
H_{c}=\frac{\mu b m_{e} \chi}{c e \mu_{0} \tau B_{e}(0)} \sqrt{n_{d}} .
$$


Выполним численные оценки критического магнитного поля. Для типичных значений $b=3 \cdot 10^{-10} \mathrm{~m}, \chi=10^{-1}$, $n_{d}=10^{-2}-10^{-4}, e=1.6 \cdot 10^{-19} \mathrm{~K}, m_{e}=9.1 \cdot 10^{-31} \mathrm{~kg}$, $\mu_{0}=4 \pi \cdot 10^{-7} \mathrm{H} / \mathrm{m}, \mu=5 \cdot 10^{10} \mathrm{~Pa}, c=3 \cdot 10^{3} \mathrm{~m} / \mathrm{s}$ получим значение $H_{c}=10^{6}-10^{7} \mathrm{~A} / \mathrm{m}$.

Отметим, что в работе [11] обнаружено влияние постоянного магнитного поля на неустойчивость пластического течения (эффект Портевена-Ле Шателье) в закаленных кристаллах $\mathrm{NaCl}: \mathrm{Eu}$ при комнатных температуpax. Действие магнитного поля приводит к уменьшению предела текучести, снижению вероятности возникновения и амплитуды скачков пластической деформации, а также к хаотизации распределения скачков по величине. Полосы сдвига на поверхности кристаллов, деформированных в магнитном поле, образуются вдвое реже, чем в кристаллах, деформированных в отсутствие поля. Однако механизм влияния магнитного поля на пластическую деформацию в этом случае принципиально иной и не связан с электронным торможением дислокаций.

Проведение целенаправленных экспериментов по подавлению скачков деформации при низких температурах поможет глубже понять физическую сущность этого явления и найти новые способы устранения этих скачков.

\section{Список литературы}

[1] Mayer P.N., Mayer A.E. // J. Appl. Phys. 2016. V. 120. N 7. P. 075901.

[2] Горбатенко В.В., Данилов В.И., Зуев Л.Б. // ЖТФ. 2017. T. 87. В. 3. C. $372-377$.

[3] Шибков А.А., Денисов А.А., Желтов М.А., Золотов А.Е., Гасанов М.Ф., Кочегаров С.С. // ФТТ. 2015. Т. 57. В. 2. C. $228-236$.

[4] Пустовалов В.В. // ФНТ. 2008. Т. 34. № 9. С. 871-913.

[5] Варюхин В.Н., Малашенко В.В. // Изв. РАН. Сер. физ. 2018. T. 82. № 9. C. 37-42.

[6] Vigueras E., Krokhin A.A., McKrell T.J., Galligan J.M. // Phil. Mag. A. 2001. V. 81. N 1. P. 137-144.

[7] Karpov E.V., Larichkin A.Yu. // J. Appl. Mech. Tech. Phys. 2017. V. 58. N 6. P. $1130-1137$.

[8] Li Z., Li N., Wang D., Ouyang D., Liu L. // Sci. Rep. 2016. V. 6. P. 29973. DOI: 10.1038/srep29973

[9] Каганов М.И., Кравченко В.Я., Начик В.Д. // УФН. 1973. T. 111. № 4. C. 655-682.

[10] Малашенко В.В. // ФНТ. 2008. Т. 34. № 9. С. 970-974.

[11] Дунин-Барковский Л.Р., Моргунов Р.Б., Tanimoto Y. // ФТТ. 2005. T. 47. В. 7. С. $1241-1246$.

[12] Малашенко В.В. // Письма в ЖТФ. 2018. Т. 44. В. 18. C. 47-52.

[13] Малашенко В.В. // Письма в ЖТФ. 2017. Т. 43. В. 17. C. $36-40$.

[14] Malashenko V.V. // Physica B. 2009. V. 404. N 2. P. 3890 3892. 